\title{
Evolution of the prostate cancer genome towards resistance
}

\author{
Francesca Lorenzin ${ }^{1}$, Francesca Demichelis ${ }^{1,2}$ \\ 'Department of Cellular, Computational and Integrative Biology, University of Trento, Trento 38123, Italy. \\ ${ }^{2}$ Englander Institute for Precision Medicine, New York Presbyterian Hospital-Weill Cornell Medicine, New York, NY 10065, USA.
}

Correspondence to: Prof. Francesca Demichelis, Department of Cellular, Computational and Integrative Biology, University of Trento, Via Sommarive 9, Trento 38123, Italy. E-mail: f.demichelis@unitn.it

How to cite this article: Lorenzin F, Demichelis F. Evolution of the prostate cancer genome towards resistance. J Trans/ Genet Genom 2019;3:5. https://doi.org/10.20517/jtgg.2019.01

Received: 20 Jan 2019 First Decision: 22 Jan 2019 Revised: 30 Jan 2019 Accepted: 1 Feb 2019 Published: 12 Mar 2019

Science Editor: David N. Cooper Copy Editor: Cai-Hong Wang Production Editor: Huan-Liang Wu

\begin{abstract}
The clinical behavior of prostate cancer is highly heterogeneous, with most patients diagnosed with localized disease that successfully responds to surgery or radiotherapy or that can be followed by active surveillance. However, a fraction of men will relapse after initial treatment and eventually progress to an aggressive resistant form with metastasis spreading and high mortality, a state referred to as castration resistant prostate cancer (CRPC). The technological advances in next generation sequencing have enabled the deep genomic and epigenomic characterization of both the hormone naïve and CRPC states, leading to the definition of molecular subclasses of prostate cancer that could inform the clinicians on therapeutic strategies. These studies also shed light on the mechanisms driving resistance to therapy. CRPCs adapt to androgen receptor (AR) signaling impairment - which follows first-line therapies as androgen deprivation or AR targeting - by restoring the nuclear receptor signaling by means of multiple mechanisms. Alternatively, tumor cells might become resistant to targeted therapies by exploiting lineage plasticity and activating alternative pathways. This review will discuss the main mechanisms leading to the emergence of resistance to therapy in prostate cancer patients in the context of genomic and molecular features of CRPC and on their causal role in the development of resistance.
\end{abstract}

Keywords: Prostate cancer, cancer evolution, resistance mechanisms, androgen receptor, metastases, castration resistant prostate cancer, genomics, epigenetics

\section{INTRODUCTION}

Prostate cancer (PCa) is the most common malignancy diagnosed among men in the US and is a major cause of death with 164,690 new estimated cases in 2018 and 29,430 expected deaths ${ }^{[1]}$. PCa is a clinically

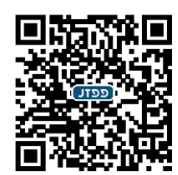


and genetically heterogeneous disease. Although the 5-year relative survival rate of patients diagnosed with localized disease is higher than $99 \%$, a minority of patients progress to an aggressive form with metastasis spreading and high mortality ${ }^{[1]}$.

At disease initiation, PCa relies on the androgen receptor (AR) signaling pathway for growth. Hence, the mainstay of therapy for PCa is represented by androgen deprivation therapy (ADT) as initially described by landmark work of Charles Huggins and colleagues in $1941^{[2,3]}$. At recurrence upon prostatectomy or radiotherapy, ADT usually involves ablation of androgen synthesis through chemical castration by administration of gonadotropin-releasing hormone agonists and antagonists and the use of competitive androgen receptor antagonists to further impede AR signaling. Despite this first-line therapy, most PCas adapt to androgen deprivation and restore AR signaling in the setting of low androgen production, a state referred to as castration-resistant prostate cancer (CRPC). The development of next-generation AR pathway inhibitors, such as abiraterone and enzalutamide ${ }^{[4-7]}$, allowed for survival benefits to patients with CRPC thanks to their ability to inhibit de novo androgen synthesis or to bind to and inactivate AR itself, respectively. However, drug resistance ultimately emerges.

\section{GENOMICS OF ADVANCED AND LOCALIZED DISEASE}

The genomics of PCa has been more challenging to study with respect to other solid tumor types due to multiple reasons, including intra-patient tumor heterogeneity and prevalence of structural genomic changes ${ }^{[8]}$. In the past ten years, technological advances in next generation sequencing finally facilitated the deep genomic and epigenomic characterization of hormone naïve and castration resistant disease. This led to a more refined definition of molecular subclasses that could ultimately be used by clinicians to adjust the therapeutic strategies when resistance emerges. Over the last decade, a plethora of studies based on tumor tissue analyses (from prostatectomies, tissue biopsies or rapid autopsy program samples) has been published. More recently, the development of genomic and molecular profiling of prospectively collected liquid biopsy samples from individual patients has improved the critical evaluation of ongoing therapies thanks to the timely detection of mutations that arise in the resistant tumors.

Primary prostate cancers are usually characterized by a diploid genome, low mutational burden, genomic rearrangements mainly involving the ETS genes and copy number aberrations, including deletions and amplifications. The overall genomic burden is associated with tumor grade ${ }^{[9-12]}$ and with biochemical recurrence ${ }^{[13,14]}$. Large and complex chromosomal rearrangements - such as chromoplexy and chromothripsis - are also prominent features of the prostate cancer genome ${ }^{[15-17]}$. CRPCs are highly aneuploidic, with approximately $40 \%$ of tumors being triploid and with a higher mutational load ${ }^{[18-21]}$. The comparison of the genomic status of primary prostate tumors and CRPCs identified lesions in TP53, AR, RB1, APC and BRCA2, among others, as enriched in the latter. These studies have shed light on the genomics driving prostate cancer resistance, which includes genomic rearrangements, point mutations and epigenetic changes ${ }^{[18,22-24]}$. This review will focus on the main mechanisms driving resistance to ADT therapy in advanced tumors that is mainly achieved either by restoration of the AR signaling or by enhanced lineage plasticity and activation of alternative pathways, thereby sustaining tumor growth independently from $\mathrm{AR}^{[25]}$. The review will emphasize relevant aspects related to genomic features and functional studies reported for each mechanism of resistance [Figure 1].

\section{GENOMIC FEATURES OF AR-DEPENDENT RESISTANCE}

$A R$ is a nuclear hormone receptor that upon activation by androgens [testosterone and 5-alphadihydrotestosterone (DHT)] translocates into the nucleus and binds to specific regulatory regions [AR responsive elements (ARE); in promoters and enhancers], regulating specific target genes and promoting prostate cell proliferation and survival. 


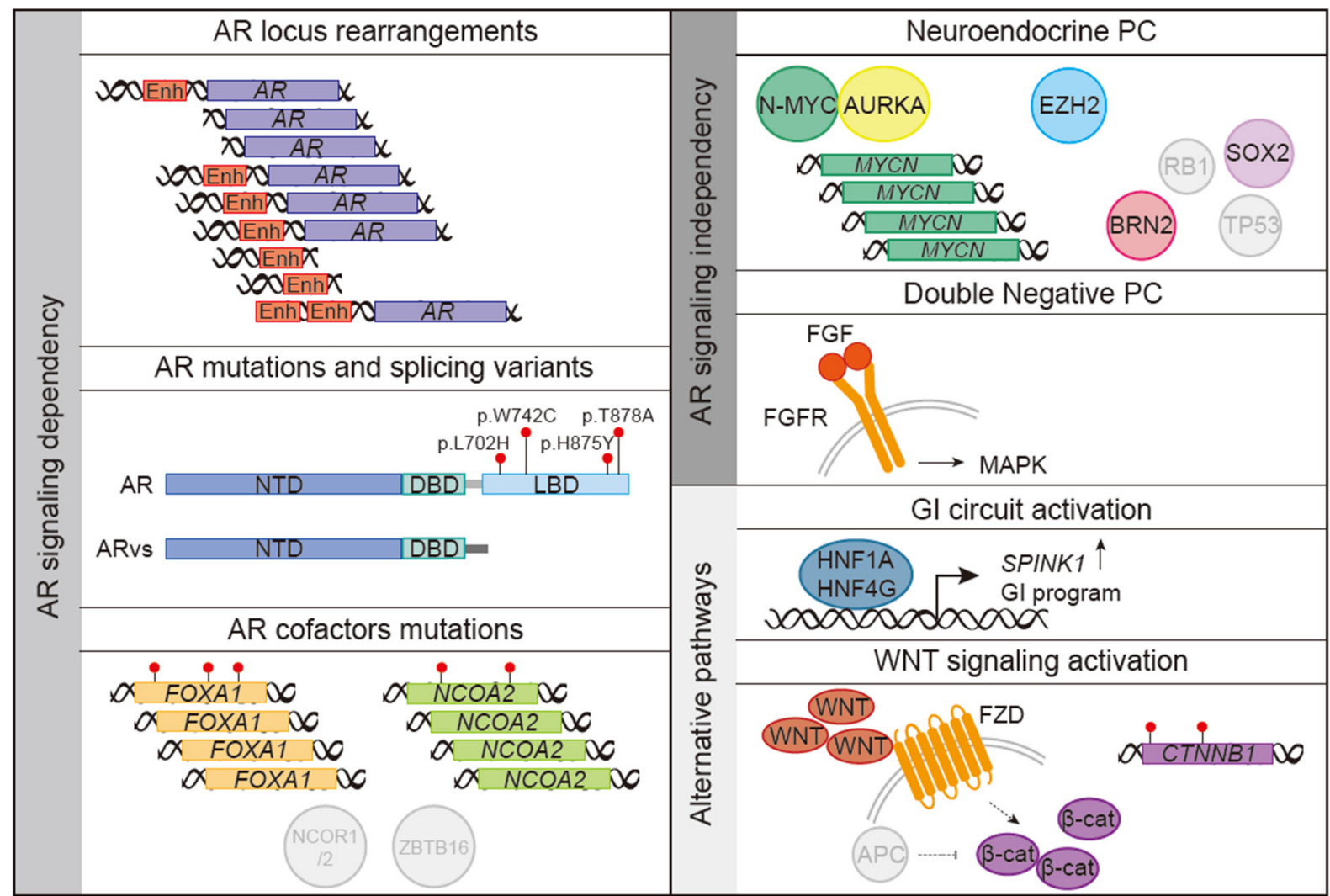

Figure 1. Schematics of the main mechanisms linked to the development of resistance to androgen deprivation therapy and androgen receptor (AR)-targeted therapies in prostate cancer. Genomic rearrangements and mutations in the $A R$ locus or its cofactors restore AR signaling promoting tumor growth. Alternatively, tumor cells transition towards an alternative AR-independent lineage showing neuroendocrine phenotype [neuroendocrine prostate cancer (NEPC)] in the setting of MYCN amplification and/or RB1 and TP53 loss. Tumors cells showing neither activation of the AR program nor neuroendocrine markers (DNPCs, double negative prostate cancer) show activation of the FGFR-MAPK pathway. Alternative pathways that promote tumor growth independently of AR include a gastrointestinal (GI) circuit controlled by specific master transcription factors and the WNT pathway. Enh: enhancer; NTD: N-terminal transactivation domain; DBD: DNA-binding domain; LBD: ligand-binding domain

Functional studies consistently demonstrated that the majority of CRPCs are still dependent on AR signaling. The mechanisms and mutations that sustain AR signaling even at low concentrations of androgens are multiple and mainly involve the $A R$ gene itself. Early investigations led to the discovery of amplification of the AR locus as possible contribution of AR to progression towards CRPC. In 1995, Visakorpi et al. ${ }^{[26]}$ reported its amplification in $30 \%$ of CRPC patients and in none of the patient-matched primary tumors before $\mathrm{ADT}^{[26]}$. Since then, work from other groups focusing on the genomic characterization of advanced prostate tumors identified AR locus amplification and gain in $>50 \%$ of cases, the most prevalent aberrations linked to resistance to AR-targeted therapy ${ }^{[1,22,24,27,28]}$. Copy number alterations of the AR locus were shown to be associated with increased expression of $\mathrm{AR}^{[29]}$ and with progression to $\mathrm{CRPC}^{[30]}$. Functional validation showed that higher levels of the receptor are indeed sufficient to promote the hormone-sensitive to hormonerefractory transition in castrated condition ${ }^{[31,32]}$. Interestingly, whole genome sequencing studies revealed that the presence of structural rearrangements in regulatory elements controlling AR expression is associated with its increased levels and with castration resistance ${ }^{[18,33]}$. Of note, copy number gain of a region upstream of the AR locus that is characterized by histone marks typically found in enhancers, can act independently of the AR locus amplification to increase AR expression levels in response to first-line $\mathrm{ADT}^{[18,33,34]}$.

AR point mutations are detected in 10\%-20\% of advanced prostate cancers upon development of treatment resistance but rarely before endocrine treatment ${ }^{[23,35,36]}$. Although early studies using PCR-based methods identified mutations in the $\mathrm{N}$-terminal transactivating domain of $\mathrm{AR}$, the next generation sequencing 
technology-based characterization identified a mutational hot spot in the ligand-binding domain of the gene $^{[19]}$, including four most frequently observed missense mutations, L702H, W742C, H875Y and T878A. These retrospectively identified point mutations are rarely detected in primary tumors, indirectly suggesting the emergence of these mutations as mechanisms to drive resistance to the therapy ${ }^{[2]}$.

Recent reports based on the analysis of cell free DNA from CRPC patient's plasma associate AR aberrations (both amplification and mutations) with worse outcome and with resistance to abiraterone and/or enzalutamide. These observations highlight the possibility of using plasma-based AR status as biomarker for therapeutic management selection ${ }^{[37-40]}$.

Studies leveraging liquid biopsy to obtain prospectively collected patients' circulating tumor DNA also allowed for the evaluation of tumor clone dynamics and demonstrated the temporal association of AR point mutations with clinical progression. Emergence of AR-L702H mutation was observed in patients receiving exogenous glucocorticoid in combination with second generation AR antagonists (enzalutamide or abiraterone), whereas $\mathrm{H} 875 \mathrm{Y}$ and T878 A AR mutations were detected at progression on abiraterone and prednisolone $e^{[41]}$. AR-L702H and T878A emerged at progression in patients treated with abiraterone ${ }^{[39]}$. F877L and other mutations were identified in a small number of patients analyzing cell free DNA and were found in CRPC patients who had progressed while on ARN-509 or enzalutamide treatment ${ }^{[37,40,42]}$.

In vitro characterization of $\mathrm{AR}$ mutants driving resistance to antiandrogens was fostered by the discovery of a mutated form of AR in the LNCaP cell line ${ }^{[43]}$. Screening using a randomly mutagenized AR library in prostate cancer cell lines under the selective pressure of enzalutamide linked the emergence of AR mutations to the development of resistance ${ }^{[44]}$. Mutations in the ligand-binding domain of AR resulted in gain-of-function by modulation of the ligand-binding affinity with increased sensitivity to other androgenic and nonandorgenic ligands, such as progesterone and glucocorticoid, which can remain at increased levels in patients treated with abiraterone ${ }^{[45,46]}$, and conversion of direct antagonists into agonists (e.g., bicalutamide, flutamide). For instance, T878A and H875Y mutants are paradoxically activated by the antiandrogens nilutamide and flutamide ${ }^{[43,47]}$. In this setting, the anti-androgens behave as an agonist leading to the activation of AR target genes. AR L702H, but not wild type AR, is activated by prednisolone and this activation at glucocorticoid concentrations found in patients is not inhibited by enzalutamide ${ }^{[4]]}$.

Expression of AR splicing variants (AR-Vs) has emerged as an additional mechanism driving resistance to first and second generation AR-targeted therapies. These alternative AR-Vs lack the C-terminal ligandbinding domain via truncation or exon skipping while retain the amino-terminal transactivation and DNA-binding domains ${ }^{[48,49]}$. Profiling of several AR-Vs revealed recruitment of these isoforms to androgen responsive elements in a ligand-independent manner, providing initial evidence for AR-Vs-sustained tumor growth without the need of ligand/androgen ${ }^{[50,51]}$. AR-V7 is the best characterized isoform, showing nuclear localization in the presence of partial nuclear localization signal, and androgen-independent activity in AR transactivation reporter ${ }^{[49,52]}$.

In prostate cancer cell-based models, the high expression of AR-Vs compared to AR full length (AR-FL) is associated with complex genomic rearrangements within the AR locus as exemplified by the 22Rv1 cell line harboring AR gene structural rearrangements and expressing high levels of AR-V7 relative to AR-FL ${ }^{[3,54]}$. Clinical data of CRPC patients also confirm that AR genomic structural rearrangements are responsible for the expression of different AR-Vs, which are able to support constitutive and ligand-independent growth of tumor cells even in presence of antiandrogens ${ }^{[55]}$. In addition, redistribution of splicing factors and high rate of $\mathrm{AR}$ gene transcription in response to $\mathrm{ADT}$ are also responsible for increased expression of $\mathrm{AR}-\mathrm{V} 7$, as shown in VCaP and in a LNCaP derivative cell line ${ }^{[56]}$.

The prognostic value of AR-Vs detection, and of AR-V7 in particular, is still unclear. AR-Vs can be detected in normal prostate tissue and early stage tumors, yet their expression seems to increase in CRPCs 
suggesting an evolutionary advantage for more aggressive disease. AR-V7 is significantly over-expressed in antiandrogen resistant tumors ${ }^{[52,57,58]}$ and its expression is associated with resistance to abiraterone and enzalutamide in two cohorts of CRPC patients ${ }^{[59,60]}$. This observation was recently confirmed in independent patients cohorts ${ }^{[61,62]}$. Moreover, AR-V7 nuclear expression in circulating tumor cells was suggested as treatment-specific biomarker for metastatic CRPC (mCRPC) patients with short survival upon enzalutamide and abiraterone treatment and increased survival benefit on taxane therapy compared to AR-targeted therapy ${ }^{[63,64]}$. However, a recent report did not support the predictive role of AR-V7 and AR-V9 detection in the circulation ${ }^{[65]}$.

A direct link for AR-V7-induced resistance to enzalutamide was provided by the restoration of sensitivity to antiandrogens in $22 \mathrm{Rv} 1$ cells depleted of $\mathrm{AR}-\mathrm{V} 7^{[66]}$. In this model AR-V7 seems to fully compensate for AR-FL function, yet other models expressing AR-V7 or other AR-Vs, such as VCaP cells, remain sensitive to androgen depletion and antiandrogens; furthermore, the growth promoting effect of AR-Vs remains dependent on AR-FL ${ }^{[7,67]}$. Recent papers investigated the genomic binding of AR-FL and AR-V7 in CRPC cells and identified AR-FL and AR-V7 co-bound sites preferentially at ARE within enhancers. Interestingly, an additional subset of genes was bound and regulated uniquely by $\mathrm{AR}-\mathrm{V} 7^{[6,696]}$. ZFX represents a crucial partner for $\mathrm{AR}-\mathrm{V} 7$ binding at promoters, and the non-canonical gene expression program regulated by the two transcription factors promotes malignant growth of CRPC cells and is associated with poor prognosis ${ }^{[68]}$.

Other mechanisms of resistance to ADT and AR-targeted therapies relying on AR and/or its regulated targets involve (1) maintenance of physiological intratumoral androgen levels, (2) dysregulated expression and/or mutation of AR cofactors, and (3) cross-regulation of AR targets by other nuclear receptors.

Following castration the levels of testosterone in circulation drop by $>90 \%$. However the adrenal androgens dehydroepiandrosterone (DHEA) and androstenedione can serve as substrates for testosterone and DHT synthesis in the prostate replenishing the pool of androgens needed by the tumor cells ${ }^{[70,71]}$. Furthermore, a gain-of-function mutation in the HSD3B1 gene was described in CRPC patients and in cell lines, such as $\mathrm{LNCaP}$ and $\mathrm{VCaP}$, as increasing the stability of the enzyme and thereby enhancing the conversion of DHEA to intratumoral $\mathrm{DHT}^{[72]}$.

Beside mutations and structural rearrangements affecting the AR locus itself, aberrations of other genes modulating the AR signaling pathway have been observed in metastatic disease ${ }^{[18,19,22,23]}$. These include point mutations and amplifications of the pioneer factor FOXA1 in 10\%-20\% of mCRPC patients ${ }^{[73]}$, amplifications/ gains and mutations of the AR coactivator $N C O A 2^{[74]}$, mutations and deletions in ZBTB16, NCOR1 or NCOR2, known AR corepressors ${ }^{[19,75]}$.

Preclinical studies and indirect evidence support the hypothesis that other nuclear receptors [e.g., glucocorticoid receptor (GR), progesterone receptor (PGR) and mineralcorticoid receptor] could substitute AR in gene regulation given the shared structure and the high homology of the DNA-binding domain ${ }^{[76]}$. Indeed, upregulation of and dependence on GR were observed in LNCaP xenograft models resistant to enzalutamide. Moreover, it was shown that AR and GR have similar cistromes and that GR overexpression mediates the induction of a subset of AR target genes thought to be involved in resistance ${ }^{[77,78]}$. More indirectly, in clinical cohorts of primary prostate cancers shorter relapse free survival was associated with high expression of PGR in situ ${ }^{[79]}$.

\section{GENOMIC FEATURES OF AR-INDEPENDENT RESISTANCE}

Lineage plasticity is recognized as one possible mechanism to evade targeted therapy where cancer cells transition towards an alternative cell lineage that is not dependent on the target. This mechanism is active in a fraction of CRPCs under AR-targeted drugs pressure. Since the introduction of second generation 
in a fraction of CRPCs under AR-targeted drugs pressure. Since the introduction of second generation AR-directed therapies in the clinical management of CRPC patients, a significant increase in tumors with a continuum of neuroendocrine markers and morphological variants was observed ${ }^{[80-83]}$ in up to $20 \%$ of resistant tumors ${ }^{[84,85]}$. These tumors demonstrate epithelial plasticity and transition towards a predominantly AR-low neuroendocrine phenotype. Elegant work from Zou et al. ${ }^{[86]}$ applied lineage tracing in vivo in genetically engineered mouse models resistant to abiraterone and developing tumors resembling treatmentinduced neuroendocrine disease in CRPC patients; the study provided quantitative evidence that both focal and overt neuroendocrine tumor regions arise via transdifferentiation from adenocarcinoma cells ${ }^{[86]}$. A model of divergent clonal evolution in CRPC from adenocarcinoma to neuroendocrine phenotype was also supported by the largest genomic and molecular study in human samples (metastatic biopsies) designed to study the etiology and molecular basis for this treatment-resistant cell state. Where the genomic component of the study recognized a substantial genomic overlap between CRPC neuroendocrine and CRPC adenocarcinomas tumors, albeit with few exceptions (enrichment for TP53 and RB1 loss and depletion of $A R$ amplification), the genome-wide methylation profiles detected marked epigenetic differences, suggesting epigenetic modifiers as possible players in the state transformation or maintenance; the transcriptomic component of the study further highlighted the dysregulation of specific pathways including neuronal and stem cell programs and epithelial-mesenchymal transition ${ }^{[87]}$.

In 2017, two studies contributed novel insights into the mechanistic understanding of cell plasticity of prostate cancer cells resistant to androgen deprivation therapies ${ }^{[8,89]}$. Altogether, they show that downregulation of TP53 and RB1 leads to increased expression of genes regulated by $\mathrm{E}_{2} \mathrm{~F}$ transcription factor, including $\mathrm{EZH}_{2}$ and $\mathrm{SOX}_{2}$; that $\mathrm{SOX}_{2}$ induction contributes to AR pathway independence and lineage reprogramming, and that $\mathrm{EZH} 2$ inhibition leads to increase in $\mathrm{AR}$ and restoration of responsiveness to enzalutamide. Additionally, SOX2 activity is controlled by a master regulator of neural differentiation, $\mathrm{BRN} 2$, which is inhibited by AR and therefore active in AR-null tumors ${ }^{[90]}$. More recently, in the attempt to look for shared vulnerabilities of small cell neuroendocrine carcinomas that arise from epithelial cancers under therapies inhibiting critical oncogenic pathways, Park and colleagues utilized human tissue transformation assays and tested the functional role of known main drivers ${ }^{[91]}$. Starting from primary basal epithelial cells isolated from the prostates of human donors and a leave-one-out approach, they observed that inactivation of both TP53 and RB1 is required to reprogram the transcriptional profile and the chromatin accessibility of normal prostate epithelial cells to small cell prostate cancer; and that the same driver events can initiate small cell lung cancer from human normal lung epithelial cells.

Building on the initial observation that AURKA and MYCN are amplified and co-overexpressed ${ }^{[92]}$ in neuroendocrine prostate cancer, Dardenne et al. ${ }^{[93]}$, using MYCN transgenic mouse and organoid models, showed that N-MYC overexpression leads to the development of poorly differentiated, invasive prostate cancer, similar to human neuroendocrine tumors. They observed abrogation of androgen receptor signaling and induction of Polycomb Repressive Complex 2 signaling. Inhibition of Aurora-A resulted in decreased steady-state levels of N-MYC protein and of its target genes and in decreased cell viability, altogether suggesting exploitation of the mutual dependence of N-MYC and Aurora-A to revert their oncogenic functions in neuroendocrine disease.

Profiling of mCRPCs patients identified a double negative population of tumors (DNPCs) that shows a lack of both the AR program and of neuroendocrine markers ${ }^{[85,94]}$. Interestingly, the proportion of DNPCs increases in cohorts of patients collected after the approval of more effective AR antagonists such as enzalutamide and abiraterone, suggesting a shift in the tumor phenotype probably linked to the use of these second generation antiandrogens ${ }^{[85]}$. In vitro work showed that these double negative cells rely on FGF and MAPK activity for growth and targeting of this AR bypass pathway can be exploited for treatment of ARnull tumors ${ }^{[85]}$. 


\section{ALTERNATIVE PROGRAMS OF RESISTANCE}

The observation that a portion of prostate cancer samples overexpresses SPINK1, a trypsin inhibitor that protects the gastrointestinal tract from protease degradation, opened up to the possibility that a gastrointestinal (GI)-lineage specific expression program is activated to promote castration resistance. Accordingly, studies showed that SPINK overexpression is associated with worse prognosis and more rapid progression of resistant tumors ${ }^{[95-98]}$ and a subclass of CRPC expresses high levels of hepatocyte nuclear factor 4-gamma $\left(\mathrm{HNF}_{4} \mathrm{G}\right)$ and 1-alpha $\left(\mathrm{HNF}_{1} \mathrm{~A}\right)^{[99]}$. These two master transcription factors sustain a GI transcriptional program in prostate cancer, present non-overlapping cistrome with $\mathrm{AR}$, and their exogenous expression leads to resistance to androgen depletion and to enzalutamide in prostate cancer cell lines and xenograft models ${ }^{[99]}$.

An alternative pathway that could sustain growth of prostate cancers is the WTN signaling pathway. Indeed, similar to colon cancers, mutations in CTNNB1 (encoding for $\beta$-catenin) genes, which lead to ligandindependent activation of the pathway, were identified in prostate cancer samples ${ }^{[100,101]}$. Recent sequencing efforts comparing the genomic feature of primary and metastatic castration resistant tumors detected mutations in major components of the WNT signaling as being enriched in the latter ${ }^{[1,22]}$. Moreover, high levels of WNT ligands are found in MCRPC samples and in vitro work supports a direct interaction between $\beta$-catenin and AR and a role for $\beta$-catenin in enhancing AR transcriptional activity ${ }^{[58,102-105]}$.

\section{CONCLUSION}

Potent therapies often trigger resistance mechanisms that present or are facilitated by distinct genomic or molecular settings. Whereas functional studies are needed to reveal the mechanistic features of drug resistance, the role of large-scale genomic studies on contemporary cohorts of patients can nominate structural events associated to resistance that can eventually turn into biomarkers for treatment options. Recent work has also suggested that complex structural events possibly involving non-coding areas of the genome can contribute to our knowledge of disease progression. $A R$ enhancer duplication ${ }^{[18,33,34]}$ and $R B 1$ exon 7-17 tandem duplication ${ }^{[106]}$ leading to AR overexpression and RB1 protein loss respectively are relevant examples of events discovered through whole genome sequencing studies. Similarly, SNPs located in noncoding inter- or intragenic regions were shown to be associated with specific subtypes of prostate cancer and with disease aggressiveness ${ }^{[107-110]}$.

The application of new therapeutic strategies to treat CRPC patients will further lead to the emergence of alternative mechanisms of resistance different from those identified so far. PARP and immune checkpoint inhibition in CRPC patients harboring defect in DNA repair pathways, such as homologous recombination and mismatch repair, and $C D K 12$ inactivation ${ }^{[19,111,112]}$ will profoundly shape the mutational landscape of prostate cancer in the future. The timely detection of mutations remains an issue of utmost importance for patient care. While liquid biopsy based studies provide promising venues to regularly monitor patients treatment response and to track tumor dynamics, proper assay design is required in order not to miss relevant new markers of resistance.

\section{DECLARATIONS}

\section{Authors' contributions}

Wrote this review: Lorenzin F, Demichelis F

\section{Availability of data and materials}

Not applicable. 


\section{Conflicts of interest}

Both authors declared that there are no conflicts of interest.

\section{Ethical approval and consent to participate}

Not applicable.

\section{Consent for publication}

Not applicable.

\section{Copyright}

(c) The Author(s) 2019.

\section{REFERENCES}

1. Siegel RL, Miller KD, Jemal A. Cancer statistics, 2018. CA Cancer J Clin 2018;68:7-30.

2. Huggins $\mathrm{C}$, Hodges CV. Studies on prostatic cancer. I. The effect of castration, of estrogen and androgen injection on serum phosphatases in metastatic carcinoma of the prostate. CA Cancer J Clin 1972;22:232-40.

3. Huggins ML. A new society for x-ray and electron diffraction research workers. Science 1941;93:489-90.

4. Barrie SE, Potter GA, Goddard PM, Haynes BP, Dowsett M, et al. Pharmacology of novel steroidal inhibitors of cytochrome P450(17) alpha (17 alpha-hydroxylase/C17-20 lyase). J Steroid Biochem Mol Biol 1994;50:267-73.

5. Chan FC, Potter GA, Barrie SE, Haynes BP, Rowlands MG, et al. 3- and 4-pyridylalkyl adamantanecarboxylates: inhibitors of human cytochrome P450(17 alpha) (17 alpha-hydroxylase/C17,20-lyase). Potential nonsteroidal agents for the treatment of prostatic cancer. J Med Chem 1996;39:3319-23.

6. Potter GA, Barrie SE, Jarman M, Rowlands MG. Novel steroidal inhibitors of human cytochrome P45017 alpha (17 alpha-hydroxylaseC17,20-lyase): potential agents for the treatment of prostatic cancer. J Med Chem 1995;38:2463-71.

7. Tran C, Ouk S, Clegg NJ, Chen Y, Watson PA, et al. Development of a second-generation antiandrogen for treatment of advanced prostate cancer. Science 2009;324:787-90.

8. Rubin MA, Demichelis F. The genomics of prostate cancer: a historic perspective. Cold Spring Harb Perspect Med 2018; doi: 10.1101/ cshperspect.a034942.

9. Cancer Genome Atlas Research Network. The molecular taxonomy of primary prostate cancer. Cell 2015;163:1011-25.

10. Rubin MA, Girelli G, Demichelis F. Genomic correlates to the newly proposed grading prognostic groups for prostate cancer. Eur Urol 2016;69:557-60.

11. Barbieri CE, Baca SC, Lawrence MS, Demichelis F, Blattner M, et al. Exome sequencing identifies recurrent SPOP, FOXA1 and MED12 mutations in prostate cancer. Nat Genet 2012;44:685-9.

12. Gandellini P, Casiraghi N, Rancati T, Benelli M, Doldi V, et al. Core biopsies from prostate cancer patients in active surveillance protocols harbor PTEN and MYC alterations. European Urology Oncology. Forthcoming 2019.

13. Camacho N, Van Loo P, Edwards S, Kay JD, Matthews L, et al. Appraising the relevance of DNA copy number loss and gain in prostate cancer using whole genome DNA sequence data. PLoS Genet 2017;13:e1007001.

14. Hieronymus H, Schultz N, Gopalan A, Carver BS, Chang MT, et al. Copy number alteration burden predicts prostate cancer relapse. Proc Natl Acad Sci U S A 2014;111:11139-44.

15. Baca SC, Prandi D, Lawrence MS, Mosquera JM, Romanel A, et al. Punctuated evolution of prostate cancer genomes. Cell 2013;153:66677.

16. Fraser M, Sabelnykova VY, Yamaguchi TN, Heisler LE, Livingstone J, et al. Genomic hallmarks of localized, non-indolent prostate cancer. Nature 2017;541:359-64.

17. Jaratlerdsiri W, Chan EKF, Petersen DC, Yang C, Croucher PI, et al. Next generation mapping reveals novel large genomic rearrangements in prostate cancer. Oncotarget 2017;8:23588-602.

18. Quigley DA, Dang HX, Zhao SG, Lloyd P, Aggarwal R, et al. Genomic hallmarks and structural variation in metastatic prostate cancer. Cell 2018;174:758-69.e9.

19. Robinson D, Van Allen EM, Wu YM, Schultz N, Lonigro RJ, et al. Integrative clinical genomics of advanced prostate cancer. Cell 2015; 161:1215-28.

20. Robinson DR, Wu YM, Lonigro RJ, Vats P, Cobain E, et al. Integrative clinical genomics of metastatic cancer. Nature 2017;548:297-303.

21. Wedge DC, Gundem G, Mitchell T, Woodcock DJ, Martincorena I, et al. Sequencing of prostate cancers identifies new cancer genes, routes of progression and drug targets. Nat Genet 2018;50:682-92.

22. Armenia J, Wankowicz SAM, Liu D, Gao J, Kundra R, et al. The long tail of oncogenic drivers in prostate cancer. Nat Genet 2018;50:645-51.

23. Grasso CS, Wu YM, Robinson DR, Cao X, Dhanasekaran SM, et al. The mutational landscape of lethal castration-resistant prostate cancer. 
Nature 2012;487:239-43.

24. Kumar A, White TA, MacKenzie AP, Clegg N, Lee C, et al. Exome sequencing identifies a spectrum of mutation frequencies in advanced and lethal prostate cancers. Proc Natl Acad Sci U S A 2011;108:17087-92.

25. Watson PA, Arora VK, Sawyers CL. Emerging mechanisms of resistance to androgen receptor inhibitors in prostate cancer. Nat Rev Cancer 2015;15:701-11.

26. Visakorpi T, Hyytinen E, Koivisto P, Tanner M, Keinanen R, et al. In vivo amplification of the androgen receptor gene and progression of human prostate cancer. Nat Genet 1995;9:401-6.

27. Menon R, Deng M, Ruenauver K, Queisser A, Peifer M, et al. Somatic copy number alterations by whole-exome sequencing implicates YWHAZ and PTK2 in castration-resistant prostate cancer. J Pathol 2013;231:505-16.

28. Robinson D, Van Allen EM, Wu YM, Schultz N, Lonigro RJ, et al. Integrative clinical genomics of advanced prostate cancer. Cell 2015;161:1215-28.

29. Linja MJ, Savinainen KJ, Saramaki OR, Tammela TL, Vessella RL, et al. Amplification and overexpression of androgen receptor gene in hormone-refractory prostate cancer. Cancer Res 2001;61:3550-5.

30. Palmberg C, Koivisto P, Kakkola L, Tammela TL, Kallioniemi OP, et al. Androgen receptor gene amplification at primary progression predicts response to combined androgen blockade as second line therapy for advanced prostate cancer. J Urol 2000;164:1992-5.

31. Waltering KK, Helenius MA, Sahu B, Manni V, Linja MJ, et al. Increased expression of androgen receptor sensitizes prostate cancer cells to low levels of androgens. Cancer Res 2009;69:8141-9.

32. Chen CD, Welsbie DS, Tran C, Baek SH, Chen R, et al. Molecular determinants of resistance to antiandrogen therapy. Nat Med 2004;10:339.

33. Viswanathan SR, Ha G, Hoff AM, Wala JA, Carrot-Zhang J, et al. Structural alterations driving castration-resistant prostate cancer revealed by linked-read genome sequencing. Cell 2018;174:433-47.e19.

34. Takeda DY, Spisak S, Seo JH, Bell C, O’Connor E, et al. A somatically acquired enhancer of the androgen receptor is a noncoding driver in advanced prostate cancer. Cell 2018;174:422-32.e13.

35. Beltran H, Yelensky R, Frampton GM, Park K, Downing SR, et al. Targeted next-generation sequencing of advanced prostate cancer identifies potential therapeutic targets and disease heterogeneity. European urology 2013;63:920-6.

36. Taplin ME, Bubley GJ, Shuster TD, Frantz ME, Spooner AE, et al. Mutation of the androgen-receptor gene in metastatic androgenindependent prostate cancer. N Engl J Med 1995;332:1393-8.

37. Azad AA, Volik SV, Wyatt AW, Haegert A, Le Bihan S, et al. Androgen receptor gene aberrations in circulating cell-free DNA: biomarkers of therapeutic resistance in castration-resistant prostate cancer. Clin Cancer Res 2015;21:2315-24.

38. Conteduca V, Wetterskog D, Sharabiani MTA, Grande E, Fernandez-Perez MP, et al. Androgen receptor gene status in plasma DNA associates with worse outcome on enzalutamide or abiraterone for castration-resistant prostate cancer: a multi-institution correlative biomarker study. Ann Oncol 2017;28:1508-16.

39. Romanel A, Tandefelt DG, Conteduca V, Jayaram A, Casiraghi N, et al. Plasma AR and abiraterone-resistant prostate cancer. Sci Transl Med 2015;7:312re10.

40. Wyatt AW, Azad AA, Volik SV, Annala M, Beja K, et al. Genomic alterations in cell-free DNA and enzalutamide resistance in castrationresistant prostate cancer. JAMA Oncol 2016;2:1598-606.

41. Carreira S, Romanel A, Goodall J, Grist E, Ferraldeschi R, et al. Tumor clone dynamics in lethal prostate cancer. Sci Transl Med 2014;6:254ra125.

42. Joseph JD, Lu N, Qian J, Sensintaffar J, Shao G, et al. A clinically relevant androgen receptor mutation confers resistance to secondgeneration antiandrogens enzalutamide and ARN-509. Cancer Discov 2013;3:1020-9.

43. Veldscholte J, Ris-Stalpers C, Kuiper GG, Jenster G, Berrevoets C, et al. A mutation in the ligand binding domain of the androgen receptor of human LNCaP cells affects steroid binding characteristics and response to anti-androgens. Biochem Biophys Res Commun 1990;173:534-40.

44. Balbas MD, Evans MJ, Hosfield DJ, Wongvipat J, Arora VK, et al. Overcoming mutation-based resistance to antiandrogens with rational drug design. Elife 2013;2:e00499.

45. Chen EJ, Sowalsky AG, Gao S, Cai C, Voznesensky O, et al. Abiraterone treatment in castration-resistant prostate cancer selects for progesterone responsive mutant androgen receptors. Clin Cancer Res 2015;21:1273-80.

46. Zhao XY, Malloy PJ, Krishnan AV, Swami S, Navone NM, et al. Glucocorticoids can promote androgen-independent growth of prostate cancer cells through a mutated androgen receptor. Nat Med 2000;6:703-6.

47. Tan J, Sharief Y, Hamil KG, Gregory CW, Zang DY, et al. Dehydroepiandrosterone activates mutant androgen receptors expressed in the androgen-dependent human prostate cancer xenograft CWR22 and LNCaP cells. Mol Endocrinol 1997;11:450-9.

48. Dehm SM, Schmidt LJ, Heemers HV, Vessella RL, Tindall DJ. Splicing of a novel androgen receptor exon generates a constitutively active androgen receptor that mediates prostate cancer therapy resistance. Cancer Res 2008;68:5469-77.

49. Hu R, Dunn TA, Wei S, Isharwal S, Veltri RW, et al. Ligand-independent androgen receptor variants derived from splicing of cryptic exons signify hormone-refractory prostate cancer. Cancer Res 2009;69:16-22.

50. Lu J, Lonergan PE, Nacusi LP, Wang L, Schmidt LJ, et al. The cistrome and gene signature of androgen receptor splice variants in castration resistant prostate cancer cells. J Urol 2015;193:690-8.

51. Chan SC, Selth LA, Li Y, Nyquist MD, Miao L, et al. Targeting chromatin binding regulation of constitutively active AR variants to overcome prostate cancer resistance to endocrine-based therapies. Nucleic Acids Res 2015;43:5880-97.

52. Guo Z, Yang X, Sun F, Jiang R, Linn DE, et al. A novel androgen receptor splice variant is up-regulated during prostate cancer progression 
and promotes androgen depletion-resistant growth. Cancer Res 2009;69:2305-13.

53. Li Y, Alsagabi M, Fan D, Bova GS, Tewfik AH, et al. Intragenic rearrangement and altered RNA splicing of the androgen receptor in a cellbased model of prostate cancer progression. Cancer Res 2011;71:2108-17.

54. Li Y, Hwang TH, Oseth LA, Hauge A, Vessella RL, et al. AR intragenic deletions linked to androgen receptor splice variant expression and activity in models of prostate cancer progression. Oncogene 2012;31:4759-67.

55. Henzler C, Li Y, Yang R, McBride T, Ho Y, et al. Truncation and constitutive activation of the androgen receptor by diverse genomic rearrangements in prostate cancer. Nat Commun 2016;7:13668.

56. Liu LL, Xie N, Sun S, Plymate S, Mostaghel E, et al. Mechanisms of the androgen receptor splicing in prostate cancer cells. Oncogene 2014;33:3140-50.

57. Hornberg E, Ylitalo EB, Crnalic S, Antti H, Stattin P, et al. Expression of androgen receptor splice variants in prostate cancer bone metastases is associated with castration-resistance and short survival. PLoS One 2011;6:e19059.

58. Miyamoto DT, Zheng Y, Wittner BS, Lee RJ, Zhu H, et al. RNA-Seq of single prostate CTCs implicates noncanonical Wnt signaling in antiandrogen resistance. Science 2015;349:1351-6.

59. Antonarakis ES, Lu C, Wang H, Luber B, Nakazawa M, et al. AR-V7 and resistance to enzalutamide and abiraterone in prostate cancer. N Engl J Med 2014;371:1028-38.

60. Efstathiou E, Titus M, Wen S, Hoang A, Karlou M, et al. Molecular characterization of enzalutamide-treated bone metastatic castrationresistant prostate cancer. Eur Urol 2015;67:53-60.

61. Antonarakis ES, Lu C, Luber B, Wang H, Chen Y, et al. Clinical significance of androgen receptor splice variant-7 mRNA detection in circulating tumor cells of men with metastatic castration-resistant prostate cancer treated with first- and second-line abiraterone and enzalutamide. J Clin Oncol 2017;35:2149-56.

62. Del Re M, Biasco E, Crucitta S, Derosa L, Rofi E, et al. The Detection of androgen receptor splice variant 7 in plasma-derived exosomal RNA strongly predicts resistance to hormonal therapy in metastatic prostate cancer patients. Eur Urol 2017;71:680-7.

63. Scher HI, Lu D, Schreiber NA, Louw J, Graf RP, et al. Association of AR-V7 on circulating tumor cells as a treatment-specific biomarker with outcomes and survival in castration-resistant prostate cancer. JAMA Oncol 2016;2:1441-9.

64. Scher HI, Graf RP, Schreiber NA, Jayaram A, Winquist E, et al. Assessment of the validity of nuclear-localized androgen receptor splice variant 7 in circulating tumor cells as a predictive biomarker for castration-resistant prostate cancer. JAMA Oncol 2018;4:1179-86.

65. To SQ, Kwan EM, Fettke HC, Mant A, Docanto MM, et al. Expression of androgen receptor splice variant 7 or 9 in whole blood does not predict response to androgen-axis-targeting agents in metastatic castration-resistant prostate cancer. Eur Urol 2018;73:818-21.

66. Li Y, Chan SC, Brand LJ, Hwang TH, Silverstein KA, et al. Androgen receptor splice variants mediate enzalutamide resistance in castrationresistant prostate cancer cell lines. Cancer Res 2013;73:483-9.

67. Watson PA, Chen YF, Balbas MD, Wongvipat J, Socci ND, et al. Constitutively active androgen receptor splice variants expressed in castration-resistant prostate cancer require full-length androgen receptor. Proc Natl Acad Sci U S A 2010;107:16759-65.

68. Cai L, Tsai YH, Wang P, Wang J, Li D, et al. ZFX mediates non-canonical oncogenic functions of the androgen receptor splice variant 7 in castrate-resistant prostate cancer. Mol Cell 2018;72:341-54.e6.

69. Chen Z, Wu D, Thomas-Ahner JM, Lu C, Zhao P, et al. Diverse AR-V7 cistromes in castration-resistant prostate cancer are governed by HoxB13. Proc Natl Acad Sci U S A 2018;115:6810-5.

70. Montgomery RB, Mostaghel EA, Vessella R, Hess DL, Kalhorn TF, et al. Maintenance of intratumoral androgens in metastatic prostate cancer: a mechanism for castration-resistant tumor growth. Cancer Res 2008;68:4447-54.

71. Nishiyama T, Hashimoto Y, Takahashi K. The influence of androgen deprivation therapy on dihydrotestosterone levels in the prostatic tissue of patients with prostate cancer. Clin Cancer Res 2004;10:7121-6.

72. Chang KH, Li R, Kuri B, Lotan Y, Roehrborn CG, et al. A gain-of-function mutation in DHT synthesis in castration-resistant prostate cancer. Cell 2013;154:1074-84.

73. Kumar A, Coleman I, Morrissey C, Zhang X, True LD, et al. Substantial interindividual and limited intraindividual genomic diversity among tumors from men with metastatic prostate cancer. Nat Med 2016;22:369-78.

74. Taylor BS, Schultz N, Hieronymus H, Gopalan A, Xiao Y, et al. Integrative genomic profiling of human prostate cancer. Cancer Cell 2010;18:11-22.

75. Hodgson MC, Astapova I, Cheng S, Lee LJ, Verhoeven MC, et al. The androgen receptor recruits nuclear receptor CoRepressor (N-CoR) in the presence of mifepristone via its $\mathrm{N}$ and $\mathrm{C}$ termini revealing a novel molecular mechanism for androgen receptor antagonists. J Biol Chem 2005;280:6511-9.

76. Lu NZ, Wardell SE, Burnstein KL, Defranco D, Fuller PJ, et al. International Union of Pharmacology. LXV. The pharmacology and classification of the nuclear receptor superfamily: glucocorticoid, mineralocorticoid, progesterone, and androgen receptors. Pharmacol Rev 2006;58:782-97.

77. Arora VK, Schenkein E, Murali R, Subudhi SK, Wongvipat J, et al. Glucocorticoid receptor confers resistance to antiandrogens by bypassing androgen receptor blockade. Cell 2013;155:1309-22.

78. Sahu B, Laakso M, Pihlajamaa P, Ovaska K, Sinielnikov I, et al. FoxA1 specifies unique androgen and glucocorticoid receptor binding events in prostate cancer cells. Cancer Res 2013;73:1570-80.

79. Grindstad T, Andersen S, Al-Saad S, Donnem T, Kiselev Y, et al. High progesterone receptor expression in prostate cancer is associated with clinical failure. PLoS One 2015;10:e116691.

80. Aparicio A, Logothetis CJ, Maity SN. Understanding the lethal variant of prostate cancer: power of examining extremes. Cancer Discov 2011;1:466-8. 
81. Beltran H, Tagawa ST, Park K, MacDonald T, Milowsky MI, et al. Challenges in recognizing treatment-related neuroendocrine prostate cancer. J Clin Oncol 2012;30:e386-9.

82. Beltran H, Tomlins S, Aparicio A, Arora V, Rickman D, et al. Aggressive variants of castration-resistant prostate cancer. Clin Cancer Res 2014;20:2846-50.

83. Wang HT, Yao YH, Li BG, Tang Y, Chang JW, et al. Neuroendocrine prostate cancer (NEPC) progressing from conventional prostatic adenocarcinoma: factors associated with time to development of NEPC and survival from NEPC diagnosis-a systematic review and pooled analysis. J Clin Oncol 2014;32:3383-90.

84. Aggarwal R, Huang J, Alumkal JJ, Zhang L, Feng FY, et al. Clinical and genomic characterization of treatment-emergent small-cell neuroendocrine prostate cancer: a multi-institutional prospective study. J Clin Oncol 2018;36:2492-503.

85. Bluemn EG, Coleman IM, Lucas JM, Coleman RT, Hernandez-Lopez S, et al. Androgen receptor pathway-independent prostate cancer is sustained through FGF signaling. Cancer Cell 2017;32:474-89.e6.

86. Zou M, Toivanen R, Mitrofanova A, Floch N, Hayati S, et al. Transdifferentiation as a mechanism of treatment resistance in a mouse model of castration-resistant prostate cancer. Cancer Discov 2017;7:736-49.

87. Beltran H, Prandi D, Mosquera JM, Benelli M, Puca L, et al. Divergent clonal evolution of castration-resistant neuroendocrine prostate cancer. Nat Med 2016;22:298-305.

88. Ku SY, Rosario S, Wang Y, Mu P, Seshadri M, et al. Rb1 and Trp53 cooperate to suppress prostate cancer lineage plasticity, metastasis, and antiandrogen resistance. Science 2017;355:78-83.

89. Mu P, Zhang Z, Benelli M, Karthaus WR, Hoover E, et al. SOX2 promotes lineage plasticity and antiandrogen resistance in TP53- and RB1-deficient prostate cancer. Science 2017;355:84-8.

90. Bishop JL, Thaper D, Vahid S, Davies A, Ketola K, et al. The master neural transcription factor BRN2 is an androgen receptor-suppressed driver of neuroendocrine differentiation in prostate cancer. Cancer Discov 2017;7:54-71.

91. Park JW, Lee JK, Sheu KM, Wang L, Balanis NG, et al. Reprogramming normal human epithelial tissues to a common, lethal neuroendocrine cancer lineage. Science 2018;362:91-5.

92. Beltran H, Rickman DS, Park K, Chae SS, Sboner A, et al. Molecular characterization of neuroendocrine prostate cancer and identification of new drug targets. Cancer Discovery 2011;1:487-95.

93. Dardenne E, Beltran H, Benelli M, Gayvert K, Berger A, et al. N-Myc induces an EZH2-mediated transcriptional program driving neuroendocrine prostate cancer. Cancer Cell 2016;30:563-77.

94. Wang W, Epstein JI. Small cell carcinoma of the prostate. A morphologic and immunohistochemical study of 95 cases. Am J Surg Pathol 2008;32:65-71.

95. Johnson MH, Ross AE, Alshalalfa M, Erho N, Yousefi K, et al. SPINK1 defines a molecular subtype of prostate cancer in men with more rapid progression in an at risk, natural history radical prostatectomy cohort. J Urol 2016;196:1436-44.

96. Leinonen KA, Tolonen TT, Bracken H, Stenman UH, Tammela TL, et al. Association of SPINK1 expression and TMPRSS2:ERG fusion with prognosis in endocrine-treated prostate cancer. Clin Cancer Res 2010;16:2845-51.

97. Pan X, Zhang X, Gong J, Tan J, Yin X, et al. The expression profile and prognostic value of SPINK1 in initially diagnosed bone metastatic prostate cancer. Prostate 2016;76:823-33.

98. Tomlins SA, Rhodes DR, Yu J, Varambally S, Mehra R, et al. The role of SPINK1 in ETS rearrangement-negative prostate cancers. Cancer Cell 2008;13:519-28.

99. Shukla S, Cyrta J, Murphy DA, Walczak EG, Ran L, et al. Aberrant activation of a gastrointestinal transcriptional circuit in prostate cancer mediates castration resistance. Cancer Cell 2017;32:792-806.e7.

100. Chesire DR, Ewing CM, Sauvageot J, Bova GS, Isaacs WB. Detection and analysis of beta-catenin mutations in prostate cancer. Prostate 2000;45:323-34.

101. Voeller HJ, Truica CI, Gelmann EP. Beta-catenin mutations in human prostate cancer. Cancer Res 1998;58:2520-3.

102. Chen G, Shukeir N, Potti A, Sircar K, Aprikian A, et al. Up-regulation of Wnt-1 and beta-catenin production in patients with advanced metastatic prostate carcinoma: potential pathogenetic and prognostic implications. Cancer 2004;101:1345-56.

103. Chesire DR, Ewing CM, Gage WR, Isaacs WB. In vitro evidence for complex modes of nuclear beta-catenin signaling during prostate growth and tumorigenesis. Oncogene 2002;21:2679-94.

104. Truica CI, Byers S, Gelmann EP. Beta-catenin affects androgen receptor transcriptional activity and ligand specificity. Cancer Res 2000;60:4709-13.

105. Yang F, Li X, Sharma M, Sasaki CY, Longo DL, et al. Linking beta-catenin to androgen-signaling pathway. J Biol Chem 2002;277:1133644.

106. Nava Rodrigues D, Casiraghi N, Romanel A, Crespo M, Miranda S, et al. RB1 heterogeneity in advanced metastatic castration-resistant prostate cancer. Clin Cancer Res 2019;25:687-97.

107. Hua JT, Ahmed M, Guo H, Zhang Y, Chen S, et al. Risk SNP-mediated promoter-enhancer switching drives prostate cancer through lncRNA PCAT19. Cell 2018;174:564-75.e18.

108. Khurana E, Fu Y, Chakravarty D, Demichelis F, Rubin MA, et al. Role of non-coding sequence variants in cancer. Nat Rev Genet 2016;17:93-108.

109. Gao P, Xia JH, Sipeky C, Dong XM, Zhang Q, et al. Biology and clinical implications of the 19q13 aggressive prostate cancer susceptibility locus. Cell 2018;174:576-89.e18.

110. Romanel A, Garritano S, Stringa B, Blattner M, Dalfovo D, et al. Inherited determinants of early recurrent somatic mutations in prostate 
cancer. Nat Commun 2017;8:48.

111. Mateo J, Carreira S, Sandhu S, Miranda S, Mossop H, et al. DNA-repair defects and olaparib in metastatic prostate cancer. N Engl J Med 2015;373:1697-708.

112. Wu YM, Cieslik M, Lonigro RJ, Vats P, Reimers MA, et al. Inactivation of CDK12 delineates a distinct immunogenic class of advanced prostate cancer. Cell 2018;173:1770-82.e14. 